\title{
OPTIMIZATION OF MEDIUM COMPOSITION FOR ANTIBACTERIAL METABOLITE PRODUCTION FROM STREPTOMYCES SP.
}

\author{
LINDA H AL-GHAZALI ${ }^{1}$, RABAB OMRAN ${ }^{2 *}$ \\ ${ }^{1}$ Department of Clinical Laboratories, College of Applied Medical Sciences, University of Karbala, Iraq. ${ }^{2}$ Department of Biology, College of \\ Science, University of Babylon, Iraq. Email: omranaljelawi@gmail.com
}

Received: 09 May 2017, Revised and Accepted: 13 June 2017

\begin{abstract}
Objectives: This paper aimed to optimize some essential nutritional components (carbon, nitrogen, and phosphate) of fermentation medium necessary for the production of antibacterial metabolites from Streptomyces sp.

Materials and Methods: Streptomyces sp. LH9 previously isolated from desert soil in Karbala Province, Iraq. This strain produced antibiotic against 4 pathogenic bacteria, including Escherichia coli, Staphylococcus aureus, Streptococcus agalagtiae, and Pseudomonas aeruginosa. For optimizing, the essential nutritional requirements such as carbon, nitrogen, and phosphate in fermentation media different concentrations of these sources were used to improve the antibacterial metabolite production.
\end{abstract}

Results: All the studied nutritional parameters were had impacts on the antibacterial metabolite production from Streptomyces sp. LH9. The actinobacterial strain produced a highest antibiotic metabolites when was grown in the fermentation medium supplemented with $2 \%$ dextrose (as a sole carbon source), $0.05 \%$ peptone (as a sole nitrogen source), and $0.05 \% \mathrm{~K}_{2} \mathrm{HPO}_{4}$ at $\mathrm{pH} 7$ and incubated under optimal conditions; at $30^{\circ} \mathrm{C}$ with $250 \mathrm{rpm}$ (revolutions/min) agitation for 7 days.

Conclusion: Streptomyces sp. LH9 was a good producer for antibacterial against Gram-positive and Gram-negative bacteria, which required simple nutritional supplements in the fermentation medium. Furthermore, could be utilized the industrial waste for improving the production in the most economic manner.

Keywords: Streptomycetes sp., Carbon, Nitrogen, Phosphate source.

(C) 2017 The Authors. Published by Innovare Academic Sciences Pvt Ltd. This is an open access article under the CC BY license (http://creativecommons. org/licenses/by/4. 0/) DOI: http://dx.doi.org/10.22159/ajpcr.2017.v10i9.19813

\section{INTRODUCTION}

The presence of multidrug-resistant pathogenic bacteria creates the need to search for new potential antibiotics against it, which became an important area of antibiotic research in the contemporary scenario. Natural bioactive substances having unique structures have been observed to perform natural biological activities. The soil is a natural source for microorganisms and their antimicrobial products [1]. Organisms from extreme habitats have gained considerable attention in recent years because of their diversity and biological activities which come mainly from their ability to produce novel chemical compounds of high commercial value $[2,3]$.

Actinomycetes have identified as one of the major groups of the soil population, which may vary with the environment of ground type [4]. Streptomyces are filamentous bacteria with a complex life cycle. Aerial growth coincides with the production of many secondary metabolites; Streptomycesis widely recognized as industrially relevant microorganisms for their ability to produce different types of novel secondary metabolites including many clinically important antibiotics [5].

Streptomyces species produces about $75 \%$ of commercially and medically useful antibiotics [6]. They have provided more than half of the naturally occurring antibiotics discovered to date and continue to screen for useful compounds [7]. Still, microbial natural products remain the most promising source of novel antibiotics although new approaches are required to improve the efficiency of the discovery process [8].

It is well known that designing an appropriate fermentation medium is of critical importance in the production of secondary metabolites [9].
Prior knowledge and experience in developing a suitable basal medium may play a significant role in the further media optimization [10]. Production of secondary metabolites through fermentation is influenced by various environmental factors, including nutrients nitrogen, phosphorus, and carbon sources [11-13]. Furthermore, production of valuable metabolites by Streptomyces differs qualitatively and quantitatively depending on the strains used in fermentation as one of the most significantroles as sources of precursors and energies for secondary metabolite production [14]. Therefore, influences of medium components and environmental conditions are an initial and important step to improve metabolite production of the genus Streptomyces.

The primary objective of this research was studying the effects of nutritional factors (carbon, nitrogen, and phosphorous sources) on antimicrobial metabolite production under optimum fermentation conditions to formulate excellent medium for improving the antibiotic production.

\section{MATERIALS AND METHODS}

Microorganisms used in the study

Streptomyces sp. LH9 previously isolated from desert soil at Karbala Province, Iraq. This isolate was identified according to microbial, cultural, biochemical and physiological characteristics $[15,16]$. The strain produced antibiotic against Gram-positive and Gram-negative bacteria.

Four test pathogenic bacteria, including Gram-negative (Escherichia coli and Pseudomonas aeruginosa) and Gram-positive (Staphylococcus aureus and Streptococcus agalagtiae), were used as test microorganisms for evaluation the antibacterial activity of Streptomyces sp. All the 
tested pathogenic bacteria were obtained from laboratory of general health in Karbala province. All bacterial isolates were preserved in slant media at $4^{\circ} \mathrm{C}$ until used.

\section{Antibiotic production from Streptomyces sp.}

The antibacterial metabolite was produced from Streptomyces sp. LH9 using the sterile fermentation broth as a basal medium, which composed from $(\mathrm{g} / 100 \mathrm{ml}$ distilled water $): 2.5 \%$ glucose, $0.5 \%$ soybean, $0.5 \%$ $\mathrm{NaCl}, 2 \% \mathrm{~K}_{2} \mathrm{HPO}_{4}, 0.05 \% \mathrm{MgSO}_{4}$, and $0.01 \% \mathrm{CaCO}_{3}$ at $\mathrm{pH} 7$ [17].

The inoculum was separately prepared by cultivated the actinobacterial isolate on starch casein nitrate agar at $30^{\circ} \mathrm{C}$ for 7 days. Then, the liquid media ( $50 \mathrm{ml}$ media/250 ml Erlenmeyer flask) were incubated with 2 disks ( $6 \mathrm{~mm}$ in diameter) of actinobacterial inoculum and incubated at $30^{\circ} \mathrm{C}$ in a rotary shaker at $250 \mathrm{rpm}$ (revolution per minutes) for 7 days. After that, the culture broth was centrifuged at $8000 \mathrm{rpm}$ at $4^{\circ} \mathrm{C}$ for 20 minutes. The aliquot supernatant was filtered using $0.45 \mu \mathrm{m}$ membrane filter (millipore). The filtrate of actinobacterial isolate was tested as antibacterial metabolite [18].

The antibacterial activity was determined, pathogenic bacteria were grown overnight in nutrient broth at $37^{\circ} \mathrm{C}$ for $24 \mathrm{hrs}$ (O.D = 0.5; McFarland $1 \times 10^{8} \mathrm{CFU} / \mathrm{ml}$ ). The cultures of test organisms were streaked on Mueller-Hinton agar medium separately. Wells (6 $\mathrm{mm}$ in diameter) were prepared in each seeded agar plate, and each well was filled with $60 \mu \mathrm{l}$ of the aliquot supernatant containing the active metabolites [19]. The plates were kept at $4^{\circ} \mathrm{C}$ for $24 \mathrm{hrs}$ for the diffusion of the metabolites. Then, the plates were incubated at $37^{\circ} \mathrm{C}$ for $24 \mathrm{hrs}$. After the incubation period, the diameter of inhibition zones was measured. Each test was in triplicate, and the activities were shown as the mean of the diameter of the inhibition zone $[20,21]$.

\section{Optimization of culture conditions for antibiotic production}

The optimization of cultural conditions was done for improving the production of antimicrobial metabolites from selected isolate using batch culture fermentation.

\section{Carbon source}

Streptomyces sp. LH9 was grown under optimum conditions (in triplicate), including the basal medium, incubation temperature $30^{\circ} \mathrm{C}$ with shaking $250 \mathrm{rpm}$ for 7 days. The basal medium composed from $2.5 \%$ carbon source, $0.5 \%$ soybean, $0.5 \% \mathrm{NaCl}, 0.2 \% \mathrm{~K}_{2} \mathrm{HPO}_{4}, 0.05 \%$ $\mathrm{MgSO}_{4}$, and $0.01 \% \mathrm{CaCO}_{3}$ at $\mathrm{pH}$ 7. Various carbon sources $(2.5 \%)$ were separately added to the production media such as sucrose, sorbitol, dextrose, galactose, glucose, glycerol, and maltose. The basal fermentation medium without any carbon source was used as a control. All carbon sources were sterilized separately with $0.45 \mu \mathrm{m}$ millipore filter and then, added separately to the sterile basal fermentation medium under aseptic conditions [22].

The best carbon sourcequantity was determined using different concentrations of sugar ranged from $1 \%$ to $3.5 \%$, in triplicate. The antibiotic production was performed under optimal conditions.

\section{Nitrogen source}

The nitrogen source was optimized using different sources $(0.5 \%)$ were added to basal fermentation media separately, such as malt extract, soybean, peptone, beef extract, and casein. The basal medium composed of the optimum carbon source and the same nutrition components as mentioned above, except the nitrogen source was changed. The control represents the basal medium without any nitrogen sources [23]. The antibiotic production was performed under optimal conditions, incubation temperature $30^{\circ} \mathrm{C}$, and shaking $250 \mathrm{rpm}$ for 7 days, in triplicate.

The best nitrogen concentration was studied using different levels of the best nitrogen source ranged from 0.0005 to $10 / 100 \mathrm{ml}$ medium, in triplicate. The antibiotic production was performed under optimal conditions.

\section{Phosphate source}

The Streptomyces sp. LH9 isolate was grown under optimal culture conditions, the basal medium containing the optimum carbon and nitrogen sources and the other nutrition components as mentioned above, except the phosphate which was used from different sources. The phosphate sources were included $\mathrm{Na}_{2} \mathrm{HPO}_{4},\left(\mathrm{NH}_{4}\right) \mathrm{H}_{2} \mathrm{PO}_{4}, \mathrm{NaH}_{2} \mathrm{PO}_{4}$, $\mathrm{K}_{2} \mathrm{HPO}_{4}, \mathrm{KH}_{2} \mathrm{PO}_{4},\left(\mathrm{NH}_{4}\right)_{2} \mathrm{HPO}_{4}$ at concentration $0.2 \%$ and the control represents the basal medium without any phosphate sources, in triplicate.

The phosphate concentration was optimized for the highest level of antibiotic production; different levels of the best phosphate source were supplemented to the media $(0.125,0.25,0.50,1.00,2.00,4.00$, and $8.00) \mathrm{g} / 100 \mathrm{ml}$, in triplicate. The antibiotic production was performed under optimal conditions.

\section{Statistical analyses}

Data were analyzed using the SPSS version 22 software Fisher's exact with a significant value of $<0.05$.

\section{RESULTS AND DISCCUSION}

In previous research, the Streptomyces sp. LH9 strain was recovered from desert soil and preserved in starch casein nitrate agar slants at $4^{\circ} \mathrm{C}$. This strain produced antibacterial metabolites against pathogenic Gram-positive and Gram-negative bacteria, including $S$. aureus, S. agalagtiae, E. coli, and P. aeruginosa. The optimal conditions for antibiotic production were $30^{\circ} \mathrm{C}$ in shaker incubator $(250 \mathrm{rpm})$ for 7 days using basal fermentation medium composed of $(\mathrm{g} / 100 \mathrm{ml}$ distilled water): $2.5 \%$ glucose, $0.5 \%$ soybean, $0.5 \% \mathrm{NaCl}, 2 \% \mathrm{~K}_{2} \mathrm{HPO}_{4}$, $0.05 \% \mathrm{MgSO}_{4}$, and $0.01 \% \mathrm{CaCO}_{3}$ at $\mathrm{pH}$ 7. In the present study, the effect of nutrition media components such as carbon, nitrogen, and phosphate sources were investigated to formulate the excellent medium for highest antibiotic production.

\section{Carbon source}

The efficiency of antibiotic production was studied from Streptomyces sp. LH9 by growing it in media supplemented with different carbon sources (sucrose, sorbitol, dextrose, galactose, glucose, glycerol, and maltose). The results revealed that Streptomyces sp. LH9 produced variable levels of antibiotic metabolites with the variance of carbon sources of media (Fig. 1). The best carbon source was dextrose, which exhibited high ability to stimulate the antibiotic productivity.

It is possible that the carbon sources (sucrose, sorbitol, galactose, glucose, glycerol, and maltose) are utilized rapidly for the synthesis of cellular material; hence, that little would be available as carbon and energy source for antibiotic synthesis $[24,25]$. While dextrose may be a good stimulator for growth and antibiotic production in addition to other media components. It is interesting, however, to note that antibiotic formation is not solely dependent on cellular growth. This result was in agreement with that obtained by Pandey et al. [26] when some carbohydrates were investigated for their effect on the growth of Streptomyces kanamyceticus M27 and antibiotic production. Dextrose proved to be an excellent carbon source for antibiotic biosynthesis [26]. Our results also were in agreement with the result revealed by Sharon et al. [27], when they studied the effect of different carbon sources for the production of antibacterial compounds from Streptomyces sp. KOD10 and the optimal carbon source was dextrose sugar.

In our study, the dextrose was an excellent carbon source for antibiotic production from Streptomyces sp. LH9, different levels of dextrose were tested to determine the optimal concentration for antibiotic production. The results in Fig. 2 showed the dextrose at a concentration of $2 \mathrm{~g} / 100 \mathrm{ml}$ induced the maximal antibiotic level, whereas the gradual increasing in dextrose concentration up to $3.5 \mathrm{~g} / 100$ caused decreasing the yield.

These results were in agreement with Sharon et al. [27], who found the different dextrose concentration impact on Streptomyces sp. 
KOD10 growth and antibiotic production, but the maximum dextrose concentration for excellent antibiotic production was $1.5 \%$.

\section{Nitrogen source}

For investigating the influence of nitrogen source on the antimicrobial metabolite production from Streptomyces sp. LH9, different nitrogen sources (malt extract, yeast extract, peptone, beef extract, and casein) were detected. The results showed the excellent nitrogen source was peptone, whereas the other sources (malt extract, yeast extract, beef extract, and casein) appeared less efficiency in supporting the production of antibacterial metabolites as shown in Fig. 3.

These results were consistent with the results of Oskay [28], who found the excellent nitrogen source for antimicrobial production from

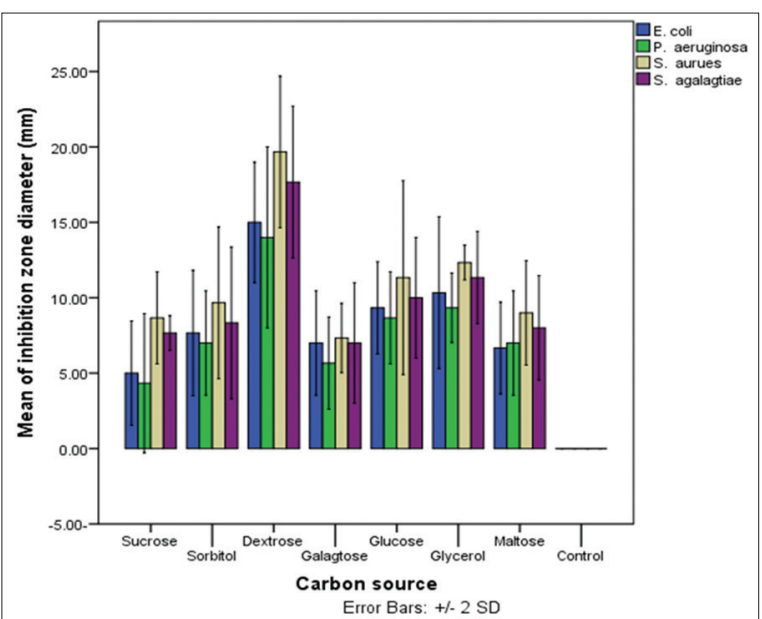

Fig. 1: Effect of carbon sources on the antibacterial metabolite production from Streptomyces sp. LH9

The actinobacterial strain was grown in liquid media containing 2.5\% carbon source at $\mathrm{pH} 7,30^{\circ} \mathrm{C}$ and $250 \mathrm{rpm}$ for 7 days. The antibiotic activities were measured according to the agar diffusion method using

Mueller-Hinton agar; each well (6 $\mathrm{mm}$ in diameter) was filled with $60 \mu \mathrm{l}$ of the aliquot supernatant containing actinobacterial metabolites and the plates were incubated at $37^{\circ} \mathrm{C}$ for $24 \mathrm{hrs}$.

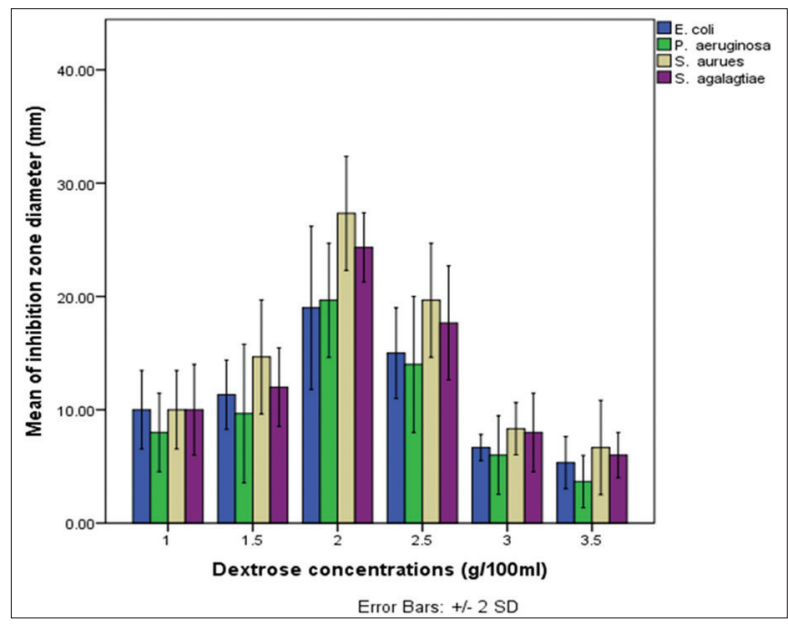

Fig. 2: Effect of dextrose concentrations on the antibacterial metabolite production from Streptomyces sp. LH9

The strain was grown in liquid media $(\mathrm{pH} 7)$ at $30^{\circ} \mathrm{C}$ and $250 \mathrm{rpm}$ for 7 days containing different concentrations of dextrose. The antibiotic activities were measured according to the agar diffusion method using

Mueller-Hinton agar; each well (6 $\mathrm{mm}$ in diameter) was filled with $60 \mu \mathrm{l}$ of the aliquot supernatant containing actinobacterial metabolites and the plates were incubated at $37^{\circ} \mathrm{C}$ for $24 \mathrm{hrs}$.
Streptomyces sp. KGG32 was peptone. Furthermore, these results were in agreement with results obtained by Ababutain et al. [29], among several nitrogen sources were tested, the peptone was preferable to produce the antibiotic from Streptomyces sp.

The nature and the availability of nitrogen from the organic and inorganic nitrogen compounds in fermentation media showed variable influences on the antibiotic levels. High yields of antibacterial compounds are favored by a tight temporal coupling between biomass accumulation and antibacterial compounds synthesis.

As peptone was the best nitrogen source for antibiotic production by Streptomyces sp., in our results, the effects of different peptone concentration the productivity of antimicrobial agent were studied. The results showed the maximum peptone concentration was required to reach maximum antibacterial metabolite production from Streptomyces sp. LH9 was $0.05 \mathrm{~g} / 100 \mathrm{ml}$ as shown in Fig. 4.

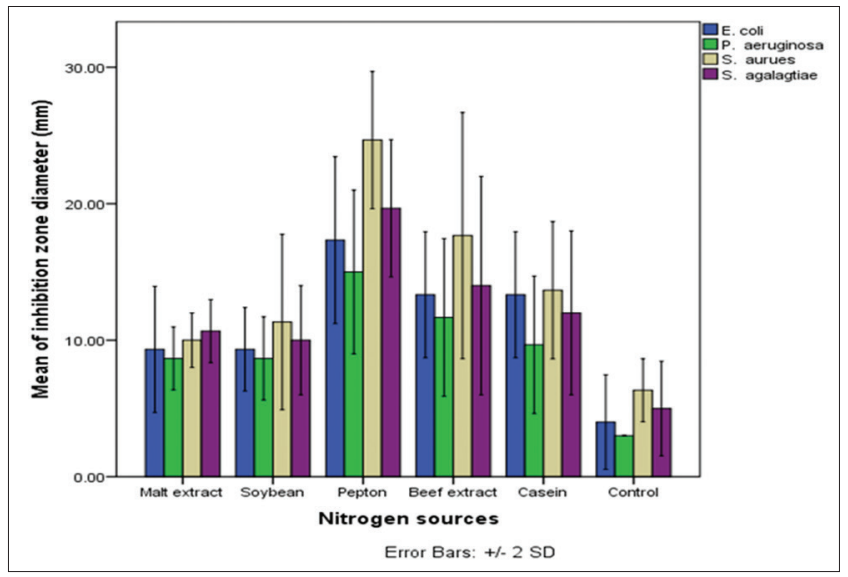

Fig. 3: Effect of nitrogen sources on the antibacterial metabolite production from Streptomyces sp. LH9

The strain was grown in liquid media $(\mathrm{pH} \mathrm{7})$ at $30^{\circ} \mathrm{C}$ and $250 \mathrm{rpm}$ for 7 days containing different nitrogen sources $(0.5 \%)$. The antibiotic activities were measured according to the agar diffusion method using

Mueller-Hinton agar; each well (6 $\mathrm{mm}$ in diameter) was filled with

$60 \mu \mathrm{l}$ of the aliquot supernatant containing actinobacterial metabolites and the plates were incubated at $37^{\circ} \mathrm{C}$ for $24 \mathrm{hrs}$.

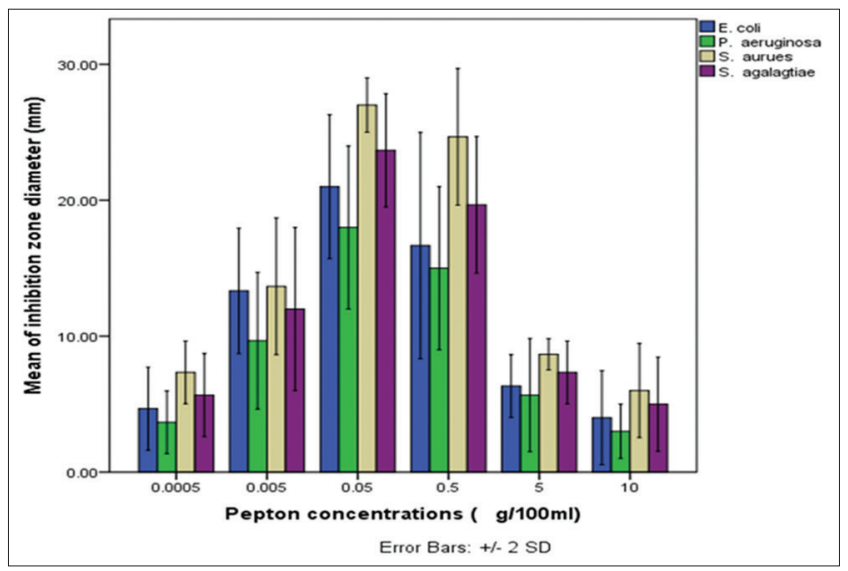

Fig. 4: Effect of peptone concentrations on the antibacterial metabolite production from Streptomyces sp. LH9

The strain was grown in liquid media $(\mathrm{pH} \mathrm{7})$ at $30^{\circ} \mathrm{C}$ and $250 \mathrm{rpm}$ for 7 days containing different concentrations of peptone. The antibiotic activities were measured according to the agar diffusion method using

Mueller-Hinton agar; each well (6 $\mathrm{mm}$ in diameter) was filled with $60 \mu \mathrm{l}$ of the aliquot supernatant containing actinobacterial metabolites and the plates were incubated at $37^{\circ} \mathrm{C}$ for $24 \mathrm{hrs}$. 
These results were consistent with results obtained by Ababutain et al. [29] how found among several peptone concentrations were tested, $0.04 \mathrm{~g} / 100 \mathrm{ml}$ peptone was preferable for antibiotic production by Streptomyces sp.

\section{Phosphate source}

Phosphate is the crucial growth-limiting nutrient in many antibiotic fermentations; hence, the effect of different phosphate source $\left(\mathrm{Na}_{2} \mathrm{HPo}_{4}\right.$, $\left.\left(\mathrm{NH}_{4}\right) \mathrm{H}_{2} \mathrm{po}_{4}, \mathrm{NaH}_{2} \mathrm{PO}_{4}, \mathrm{~K}_{2} \mathrm{HP}_{04}, \mathrm{KH}_{2} \mathrm{PO}_{4},\left(\mathrm{NH}_{4}\right)_{2} \mathrm{HPO}_{4}\right)$ was evaluated for their influence on antibiotic production from Streptomyces sp. LH9. The results showed the efficiency of different phosphate compounds in supporting the antibacterial metabolite production from actinobacterial strain. The $\mathrm{K}_{2} \mathrm{HPO}_{4}$ salt was the optimum phosphate compound for antibacterial metabolite production. While the other phosphate sources exhibited low efficiency for antibiotic production, which were evident by weak activities against tested pathogenic bacteria, as shown in Fig. 5 .

The results were in agreement with the results of Majumdar and Majumdar [30], who reported that $\mathrm{K}_{2} \mathrm{HPO}_{4}$ is required for maximum yield of neomycin which produced from Streptomyces fradiae. Furthermore, the results were consistent with the results obtained by Narayana and Vijayalakshmi [31] how found among different minerals tested, only $\mathrm{K}_{2} \mathrm{HPO}_{4}$ showed the positive effect on antibiotic production from Streptomyces albidoflavus.

As $\mathrm{K}_{2} \mathrm{HPO}_{4}$ was the best phosphate source for antibiotic production from Streptomyces sp. LH9, the consequences of supplying different concentrations $(0.125,0.25,0.50,1.00,2.00,4.00$, and 8.00$) \mathrm{g} / 100 \mathrm{ml}$ on the productivity of antimicrobial agent were studied. The results showed the different levels of inhibition zones of testing pathogenic bacteria included Gram-negative bacteria (E. coli and P. aeruginosa) and Gram-positive bacteria ( $S$. agalagtiae and $S$. aureus). Whereas the highest level was obtained by the $\mathrm{K}_{2} \mathrm{HPO}_{4}$ concentration in $0.05 \mathrm{~g} / 100 \mathrm{ml}$, but the upper or lower $\mathrm{K}_{2} \mathrm{HPO}_{4}$ concentrations caused decreases in antibiotic production from Streptomyces sp. LH9, as shown in Fig. 6.

These results were in agreement with the results of Raytapadar and Paul [32] who reported the optimum concentration of $\mathrm{K}_{2} \mathrm{HPO}_{4}$ for growth, and antibiotic production was 0.135 and $0.675 \mathrm{~g} / \mathrm{l}$.

Phosphate regulates the syntheses of antibiotics belonging to different biosynthetic groups; these include peptide antibiotics, polyene macrolides, tetracyclines, and biosynthetically sophisticated antibiotics. Industrial production of these medicines is carried out at growth-limiting concentrations of inorganic phosphate. Phosphate in concentrations ranging from 0.3 to $300 \mathrm{~m}$ supports huge cell growth, but the concentrations of $10 \mathrm{~mm}$ and above suppress the biosynthesis of many antibiotics [33]. Because of the various antimicrobial metabolites regulated by phosphate are synthesized through different pathways. Many different mechanisms may exist, or else a standard regulatory effector may act on the biosynthetic pathways [34]. Phosphate addition not only interferes with antibiotic synthesis but also after several hours causes a reversal of non-growing, antibiotic-producing cells back to a growing, non-producing state [35].

\section{CONCLUSION}

Streptomyces sp. LH9 was a good producer for antibacterial against Gram-positive and negative bacteria, which required essential nutritional supplements in the fermentation medium. Furthermore, could be utilized the industrial waste for improving the production in the most economical manner.

\section{ACKNOWLEDGMENT}

The authors are thankful to the faculty of the Laboratory of Biotechnology and Genetic Engineering, Department of Biology, College of Science, University of Babylon, Iraq.

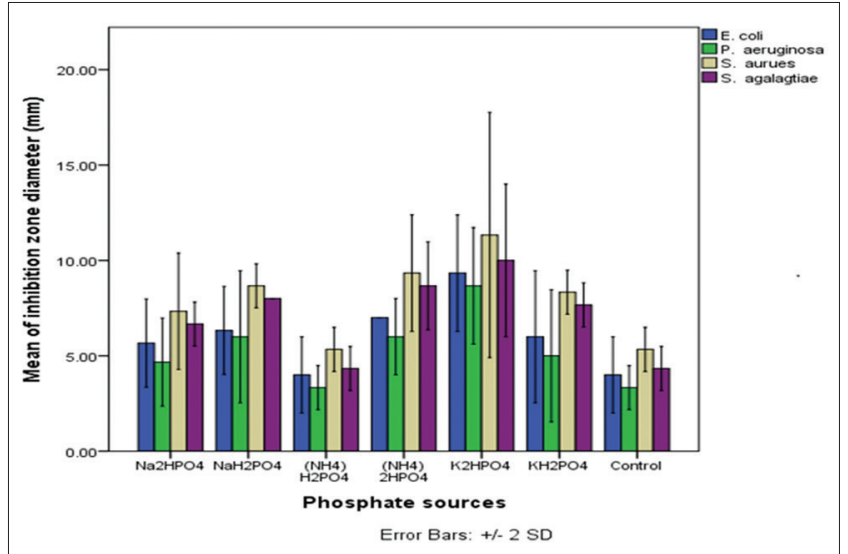

Fig. 5: Effect of phosphate sources on the antibacterial metabolite production from Streptomyces sp. LH9

The strain was grown in liquid media $(\mathrm{pH} 7)$ at $30^{\circ} \mathrm{C}$ and $250 \mathrm{rpm}$

for 7 days containing different sources of phosphate. The antibiotic activities were measured according to the agar diffusion method using

Mueller-Hinton agar; each well ( $6 \mathrm{~mm}$ in diameter) was filled with $60 \mu \mathrm{l}$ of the aliquot supernatant containing actinobacterial metabolites and the plates were incubated at $37^{\circ} \mathrm{C}$ for $24 \mathrm{hrs}$.

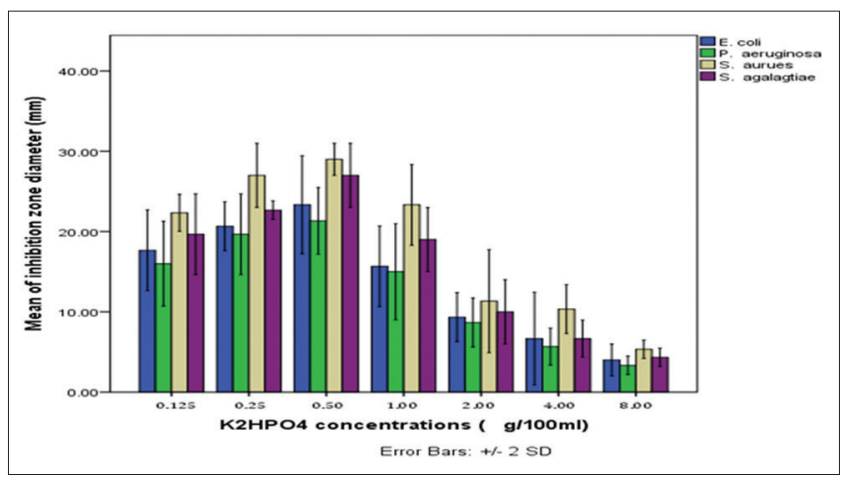

Fig. 6: Effect of $\mathrm{K}_{2} \mathrm{HPO}_{4}$ concentrations on the antibacterial metabolite production from Streptomyces sp. LH9

The strain was grown in liquid media $(\mathrm{pH} \mathrm{7})$ at $30^{\circ} \mathrm{C}$ and $250 \mathrm{rpm}$ for

7 days containing different concentrations of $\mathrm{K}_{2} \mathrm{HPO}_{4}$. The antibiotic activities were measured according to the agar diffusion method using

Mueller-Hinton agar; each well ( $6 \mathrm{~mm}$ in diameter) was filled with $60 \mu \mathrm{l}$ of the aliquot supernatant containing actinobacterial metabolites and the plates were incubated at $37^{\circ} \mathrm{C}$ for $24 \mathrm{hrs}$.

\section{REFERENCES}

1. Dancer SJ. How antibiotics can make us sick: The less obvious adverse effects of antimicrobial chemotherapy. Lancet Infect Dis 2004;4(10):611-9.

2. Amador ML, Jimeno J, Paz-Ares L, Cortes-Funes H, Hidalgo M. Progress in the development and acquisition of anticancer agents from marine sources. Ann Oncol 2003;14(11):1607-15.

3. Imada C. Enzyme inhibitors and other bioactive compounds from marine actinomycetes. Antonie Van Leeuwenhoek 2005;87(1):59-63.

4. Kuster HJ. Uber die bildung von huminstoffen durch streptomyceten. Landwirtsch Forsch 1968;21:48-61.

5. Hopwood DA. Streptomyces in Nature and Medicine: The Antibiotic Makers. USA: Oxford University Press; 2007.

6. Baltz RH. Marcel faber roundtable: Is our antibiotic pipeline unproductive because of starvation, constipation or lack of inspiration? J Ind Microbiol Biotechnol 2006;33(7):507-13.

7. Miyadoh S. Research on antibiotic screening in Japan over the last decade: A producing microorganisms approach. Actinomycetologica 1993;9:100-6.

8. Thumar JT, Dhulia K, Singh SP. Isolation and partial purification of an antimicrobial agent from halotolerant alkaliphilic Streptomyces 
aburaviensis strain Kut-8. World J Microbiol Biotechnol 2010;26:2081-7.

9. Gao H, Liu M, Liu J, Dai H, Zhou X, Liu X, et al. Medium optimization for the production of avermectin B1a by Streptomyces avermitilis 14-12A using response surface methodology. Bioresour Technol 2009;100(17):4012-6.

10. Jia B, Jin ZH, Mei LH. Medium optimization based on statistical methodologies for pristinamycins production by Streptomyces pristinaespiralis. Appl Biochem Biotechnol 2008;144:133-43.

11. Lin J, Bai L, Deng Z, Zhong JJ. Effect of ammonium in medium on ansamitocin P-3 production by Actinosynnema pretiosum. Biotechnol Bioprocess Eng 2010;15:119-25.

12. Ruiz B, Chávez A, Forero A, García-Huante Y, Romero A, Sánchez M, et al. Production of microbial secondary metabolites: Regulation by the carbon source. Crit Rev Microbiol 2010;36(2):146-67.

13. Sánchez S, Chávez A, Forero A, García-Huante Y, Romero A, Sánchez $\mathrm{M}$, et al. Carbon source regulation of antibiotic production. J Antibiot (Tokyo) 2010;63(8):442-59.

14. Wang X, Huang L, Kang Z, Buchenauer H, Gao X. Optimization of the fermentation process of actinomycete strain hhs.015. J Biomed Biotechnol 2010;2010:141876. Doi: 10.1155/2010/141876

15. Kuester E, Williams ST. Selection of media for isolation of streptomycetes. Nature 1964;202:928-9.

16. Kämpfer P. Order XIV. Streptomycetales ord. nov. In: Goodfellow M, Kampfer P, Busse HJ, Trujillo ME, Suzuki K, Ludwig W, editors. Bergey's Manual of Systematic Bacteriology. $2^{\text {nd }}$ ed. New York: Springer; 2012. p. 1446-806.

17. Gesheva V, Ivanova V, Gesheva R. Effects of nutrients on the production of AK-111-81 macrolide antibiotic by Streptomyces hygroscopicus. Microbiol Res 2005;160(3):243-8.

18. Karthick L, Kumar KG, Bhaskara RA. The diversity of marine actinomycetes from nicobar marine sediments and its antifungal activity. Int J Pharm Pharm Sci 2010;2:199-203.

19. Anansiriwattana W, Tanasupawat S, Amnuoypol S, Suwanborirux K. Identification and antimicrobial activities of actinomycetes from soils in samed Island and geldamycin from strain PC4-3. Thai J Pharm Sci 2006;30:49-56.

20. Shahrokhi S, Bonjar GH, Saadoun I. Biological control of potato isolate of Rhizoctonia solani by Streptomyces olivaceus strain 115. Biotechnology 2005;4:132-8

21. Kavanagh F. Analytical Microbiology. Vol. 2. New York: Ahead
Press; 1972.

22. Jonsbu E, McIntyre M, Nielsen J. The influence of carbon sources and morphology on nystatin production by Streptomyces noursei. J Biotechnol 2002;95(2):133-44

23. Shapiro S, Vining LC. Nitrogen metabolism and chloramphenicol production in Streptomyces venezuelae. Can J Microbiol 1983;29(12):1706-14

24. Hassan M, El-Naggar M, Said W. Physiological factors affecting the production of an antimicrobial substance by Streptomyces violatus in batch culture. Egypt J Biol 2001;3:1-10.

25. Omran R, Kadhem MF. Production, purification, and characterization of bioactive metabolites produced from rare actinobacteria Pseudonocardia alni. Asian J Pharm Clin Res 2016;9:264-72.

26. Pandey A, Shukla A, Majumdar SK. Utilization of carbon and nitrogen sources by Streptomyces kanamyceticus M 27 for the production of an antibacterial antibiotic. Afr J Biotechnol 2005;4:909-10.

27. Sharon SF, Daniel RR, Shenbagarathai R. Optimization of antibiotic productionby marineactinomycetes Streptomyces sp. Int J Pharm Pharm Sci 2014;6:506-10.

28. Oskay M. Effects of some environmental conditions on biomass and antimicrobial metabolite production by Streptomyces sp. KGG32. Int J Agric Biol 2011;13:317-24.

29. Ababutain IM, Abdul-Aziz ZK, Al-Meshhen NA. Optimization of environmental and nutritional conditions to improve growth and antibiotic productions by Streptomyces sp. Int Res J Microbiol 2013;4:179-87.

30. Majumdar MK, Majumdar SK. Effects of minerals on neomycin production by streptomyces fradiae. Appl Microbiol 1965;13:190-3.

31. Narayana KJ, Vijayalakshmi M. Optimization of antimicrobial metabolite production by Streptomyces albidoflavus. Res J Pharm 2008;2:4-7.

32. Raytapadar S, Paul AK. Production of an antifungal antibiotic by Streptomyces aburaviensis 1DA-28. Microbiol Res 2001;155(4):31523.

33. Martin JF. Control of antibiotic synthesis by phosphate. Adv Biochem Eng 1977;6:105-27.

34. Martin JF. Phosphate regulation of gene expression of candicidin biosynthesis. In: Schlessinger D, editor. Microbiology. Washington, DC: American Society for Microbiology; 1976. p. 548-52.

35. Liu CM, McDaniel LE, Schaffner CP. Studies on candicidin biogenesis. J Antibiot (Tokyo) 1972;25(2):116-21. 